\title{
Visual migraine aura with or without headache: association with right to left shunt and assessment following transcutaneous closure
}

This article was published in the following Dove Press journal:

Clinical Ophthalmology

17 July 2012

Number of times this article has been viewed

\section{Khalid Mojadidi' \\ Hamidreza Khessali' \\ Rubine Gevorgyan' \\ Ralph D Levinson ${ }^{2}$ \\ Jonathan M Tobis'}

'Division of Interventional Cardiology, David Geffen School of Medicine, University of California at Los Angeles, ${ }^{2}$ Division of Comprehensive Ophthalmology and Ocular Inflammatory Disease Center, Jules Stein Eye Institute, University of California at Los Angeles, Los Angeles, CA, USA

Video abstract

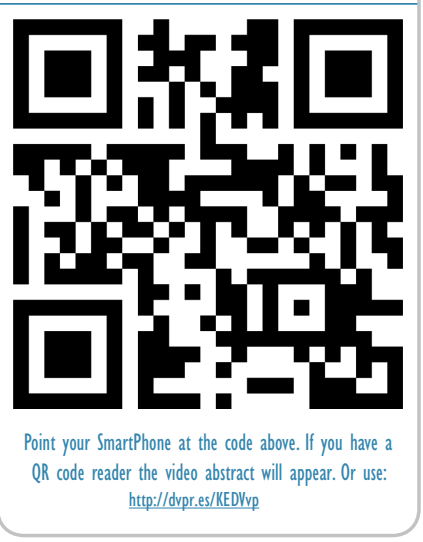

Correspondence: Jonathan Tobis Director of Interventional Cardiology, University of California at Los Angeles, B976 Factor Building CHS, 10833 Le Conte Avenue, Los Angeles,

CA 90095, USA

Tel + I 3107944797

Fax +I 3102670384

Email jtobis@mednet.ucla.edu
Background: Right to left shunting, usually caused by a patent foramen ovale (PFO), is associated with migraine and visual aura. It is unknown if patients who present with visual aura without headache behave similarly to those experiencing typical migraine headache with aura. The purpose of this study was to assess the prevalence of right to left shunting in patients who present with migraine aura without headache and evaluate the response to PFO closure.

Methods: The records of patients referred to the Interventional Cardiology program at the University of California at Los Angeles for suspected intracardiac right to left shunt were reviewed. Individuals with visual auras with or without migraine headaches were divided into three groups: group A (aura + migraine), migraine aura during or within 60 minutes of headache; group B (migraine aura unrelated to headache), migraine aura and headache temporally unrelated; and group $\mathrm{C}$ (migraine aura only), isolated migraine visual aura without a history of headaches. The presence of right to left shunt was assessed using transcranial Doppler with an agitated saline test. PFO closure was performed in 80 patients. Residual headache and migraine visual aura were assessed 3 and 12 months after the procedure. The control group consisted of 200 patients referred for diagnostic cardiac catheterization.

Results: Of 590 referred patients, 225 had migraine visual aura with or without headache. The prevalence of right to left shunt was similar $(P=0.66)$ in groups $\mathrm{B}(21 / 29,72 \%)$ and C (14/21, 67\%). Group A patients had a higher prevalence of right to left shunt (168/175, $96 \%$ ) due to selection bias. The prevalence of right to left shunt in the control group was significantly $(P<0.0001)$ lower $(36 / 200,18 \%)$ than in groups A, B, and C. At 12 months after PFO closure, visual aura was resolved in $52 \%, 75 \%$, and $80 \%$ of patients in groups A, $\mathrm{B}$, and $\mathrm{C}$, respectively (difference not statistically significant).

Conclusion: There is an increased prevalence of PFO among patients with migraine aura without headache. The closure of PFO correlates with improvement of the visual aura, suggesting a causative association between the presence of PFO and both visual aura and migraine headaches. Ophthalmologists should be aware of the association of right to left shunts with visual aura.

Keywords: visual aura without headache, right to left shunt, patent foramen ovale

\section{Introduction}

Transient visual disturbances are associated with migraine headache in $20 \%$ of people with migraine. ${ }^{1,2}$ When these visual symptoms precede or occur during a headache, they are recognized as visual aura associated with migraine. However, there are some patients who develop visual aura that is not associated with a headache. In these cases, the patient or the physician may be concerned that there is a primary ocular problem, such as vitreoretinal traction with or without a retinal tear, optic nerve disease, or a nonmigrainous process involving the central nervous system, such as a transient 
ischemic event or a cortical stroke. Isolated migraine visual aura without headache is present in $3.2 \%$ of the general population. ${ }^{2}$ It is not uncommon for individuals who describe such visual phenomenon without headache to present to an ophthalmologist first. Approximately $2 \%$ of individuals more than 50 years of age in our university-based comprehensive ophthalmology practice were seen over a three-year period for visual aura without headache (unpublished data).

Migraine headache, present in about $12 \%$ of the general population, is one of the most frequent causes of disability in the US. ${ }^{3}$ There is an association between migraine with aura and intracardiac or pulmonary venous to arterial shunting of blood. Right to left shunting of blood commonly occurs through a patent foramen ovale (PFO). Although shunting through a PFO is usually directed from the left atrium to the right atrium, the Valsalva maneuver or straining causes right atrial pressure to exceed left atrial pressure, resulting in transient reversal of flow.

While PFO is present in $20 \%$ of the general population, ${ }^{3-5}$ this proportion increases to $50 \%-60 \%$ in people who have migraine headaches associated with visual aura. ${ }^{6-9}$ Whereas visual aura without headache is thought to be a form of migraine (and has been referred to as acephalgic migraine), it is not known whether these visual phenomena share the same pathophysiology that migraine headache does with right to left shunting. To answer this question, the frequency of right to left shunting in patients with visual auras with or without headaches was examined. In addition, it was assessed whether closure of the PFO resulted in a lower frequency of visual auras.

\section{Materials and methods}

The records of all patients referred to the interventional cardiology program in the University of California at Los Angeles between 2001-2011 for assessment of conditions associated with PFO, including cryptogenic stroke, migraines, decompression illness, and orthodeoxia, were reviewed. All patients were asked about the presence of migraine headaches and visual aura, and specifically whether transient visual symptoms occurred with or without headaches. For the purpose of this study, visual aura was defined in accordance with the International Classification of Headache Disorders-II (ICHD-II) as typical aura without headache, consisting of fully reversible visual symptoms including positive features (flickering lights, spots, or lines) and/or negative features (loss of vision). These symptoms are characterized by gradual development, duration no longer than one hour, a mixture of positive and negative features, and complete reversibility. ${ }^{1}$ Patient responses were used to classify the patients into three groups. Group A comprised patients with visual aura associated with migraine headache, in whom the visual aura fulfilled the diagnostic criteria of the ICHD-II for "typical aura with migraine headaches". Group B included patients with visual aura not associated with migraine headache, who had both visual aura and migraine headaches, but no temporal association between them. Migraine headaches were present in this group, but met the ICHD-II criterion that "headache does not occur during aura nor follow aura within 60 minutes". Group C included patients with visual aura without a history of headache, and were characterized by the presence of typical visual aura, as seen in migraineurs, but without any history of migraine headaches. ${ }^{1}$

The patients were screened for the presence of a right to left shunt using a transcranial Doppler study with a power M-mode Terumo 150 PMD machine (Spencer Technologies, Seattle, WA). A mixture of $8 \mathrm{cc}$ normal saline combined with $0.5 \mathrm{cc}$ of air and $1 \mathrm{cc}$ of blood was agitated between two syringes connected by a three-way stopcock and injected into the brachial vein. Embolic tracks were then counted over the middle cerebral arteries. The degree of right to left shunt was evaluated by transcranial Doppler at rest and with the Valsalva maneuver at $40 \mathrm{mmHg}$, aided by visual feedback using a manometer. ${ }^{10}$ The Spencer Logarithmic Scale was used to grade the results, whereby grade 3 and higher ( $\geq 31$ embolic tracks/60 seconds) was considered to be positive for a significant shunt. ${ }^{11}$

Patients with a history of stroke or severe debilitating migraines had their PFO closed percutaneously. The decision to close the PFO was made by the patient and their physician based on clinical concerns. The patients were not randomized for the purposes of this study, although six patients (7.5\%) were already participating in multicenter randomized trials for $\mathrm{PFO}$ closure, ie, the RESPECT trial for cryptogenic stroke or the PREMIUM trial for severe debilitating migraine headaches. Post-closure assessment consisted of a follow-up history and transcranial Doppler at three-monthly intervals for up to one year or until complete resolution of the shunt, as evidenced by a negative transesophageal echocardiogram and negative transcranial Doppler. Following PFO closure, the patients' visual symptoms and migraines were categorized as:

- Resolved, with complete resolution of visual aura (and headache where applicable)

- Improved, with $\geq 50 \%$ reduction in number of aura events (and headache days per month where applicable)

- Worse, with $\geq 50 \%$ increase in the number of aura (and headache days per month where applicable)

- No change, with symptoms remaining the same $(<50 \%$ change) following PFO closure 
Table I Clinical descriptors of the three groups of patients with visual aura

\begin{tabular}{|c|c|c|c|c|c|}
\hline & $\begin{array}{l}\text { Group A } \\
\text { MH + aura }\end{array}$ & $\begin{array}{l}\text { Group B } \\
\text { MH + aura } \\
\text { (unrelated in time) }\end{array}$ & $\begin{array}{l}\text { Group C } \\
\text { aura only }\end{array}$ & Controls & $P$ value \\
\hline Total number & 175 & 29 & 21 & 200 & \\
\hline Age & $48 \pm 13$ & $49 \pm 15$ & $44 \pm 14$ & $54 \pm 17$ & 0.99 \\
\hline Male & $56(32 \%)$ & $10(35 \%)$ & 12 (57\%) & 98 (49\%) & 0.02 \\
\hline HTN & 27 (I5\%) & $8(28 \%)$ & $5(24 \%)$ & $72(36 \%)$ & 0.17 \\
\hline Hyperlipidemia & 27 (I5\%) & $7(24 \%)$ & $3(14 \%)$ & $90(40 \%)$ & 0.20 \\
\hline DM & 7 (4\%) & $0(0 \%)$ & $0(0 \%)$ & $28(\mid 4 \%)$ & 0.08 \\
\hline Hypercoagulability & $36(21 \%)$ & 7 (24\%) & $5(24 \%)$ & $10(5 \%)$ & 0.10 \\
\hline
\end{tabular}

Abbreviations: DM, diabetes mellitus; HTN, hypertension; $\mathrm{MH}$, migraine headache.

\section{Control population}

The control population consisted of patients who were referred to the cardiac catheterization laboratory for diagnostic catheterization unrelated to the presence of a PFO. Each person was assessed for the presence of a right to left shunt using transcranial Doppler. Patients who had cardiac transplants were excluded from the control group because they may have had a PFO closed at the time of surgery.

\section{Statistical analysis}

Continuous variables were expressed as the mean \pm standard deviation. Dichotomous variables were expressed as a percentage frequency. SPSS version 17.0 statistical software (SPSS Inc, Chicago, IL) was used for two-tailed $t$-test comparison between the groups and the control population. Analysis of variance test was used for comparison of general clinical descriptors between all groups. A $P$ value $\leq 0.05$ was considered to be statistically significant. Odds ratios were calculated in order to estimate the likelihood of patients in the three study groups and control group having a right to left shunt.

\section{Results}

Of the 590 patient records screened, 225 patients had visual aura with or without migraine headache. A separate population of 200 patients was included as the control group. Table 1 shows the clinical descriptors of the three patient populations and the control group. The only demographic difference between the groups was a higher proportion of men in Group $\mathrm{C}$ and in the control group. There was a trend towards more diabetes mellitus, hypertension, and hyperlipidemia in the control group and a trend towards more hypercoagulable conditions in all three groups with visual auras, but these variables did not reach statistical significance (Table 2).

The number of patients in each group who had a right to left shunt with visual aura and in the control group is shown in Table 3. Although the prevalence of right to left shunt was similar in Groups B and C (14/21 [67\%] and 21/29 [72\%], respectively; $P=0.66$ ), Group A patients had a significantly higher frequency of right to left shunt $(168 / 175,96 \%)$ when compared with the other two groups. The prevalence of right to left shunt in the control group $(36 / 200,18 \%)$ was significantly lower than the prevalence of right to left shunt in Groups A, B, and C $(P<0.0001)$. Compared with the controls, the odds ratio of having a PFO was 12.0 in Group B and 9.1 in Group C. All three groups were highly selected because most of the patients in these groups were referred to the interventional cardiology department as a result of a pre-existing suspicion of PFO, whether due to initial presentation with cryptogenic stroke or a previously positive agitated saline bubble study.

Among the patients with visual aura, PFO closure was performed in 80 patients, ie, 67/168 (40\%) patients in Group A, 8/21 (38\%) patients in Group B, and 5/14 (36\%) patients in Group C. Table 4 shows the distribution of PFO closure and the outcomes of this procedure in the patients. At three months, $25 \%$ of patients in Group A, $50 \%$ of patients in Group B, and $40 \%$ of patients in Group C experienced

Table 2 List of hypercoagulable conditions

Hypercoagulable conditions

OCP/HRT*

Pregnancy

Factor $V$ Leiden

Prothrombin G20210 A mutation

Antiphospholipid antibodies

Homocysteinemia

Protein S deficiency

Protein $\mathrm{C}$ deficiency

Elevated lipoprotein A

Antithrombin III deficiency

Anticardiolipin AB

Factor VIII activity

B2-glycoprotein-I AB

Thrombocystosis

Abbreviations: OCP, oral contraceptive pill; HRT, hormone replacement therapy. 
Table 3 Frequency of right to left shunt in the three groups of patients with visual aura and the number of patent foramen ovale that were closed versus controls

\begin{tabular}{lllll}
\hline & $\begin{array}{l}\text { Group A } \\
\text { MH + aura }\end{array}$ & $\begin{array}{l}\text { Group B } \\
\text { MH + aura (unrelated) }\end{array}$ & $\begin{array}{l}\text { Group C } \\
\text { aura only }\end{array}$ \\
\hline Patients per group $(\mathrm{n})$ & 175 & 29 & $2 \mathrm{I}$ & Controls \\
Positive for R to $\mathrm{L}$ shunt $(\mathrm{n})$ & $168(96 \%)$ & $2 \mathrm{I}(72 \%)$ & $14(67 \%)$ & 200 \\
& $(P<0.000 \mathrm{I}) *$ & $(P<0.000 \mathrm{I}) *$ & $0.0001)^{*}$ & $36(18 \%)$ \\
R to $\mathrm{L}$ shunts that were closed $(\mathrm{n})$ & $67(40 \%)$ & $8(38 \%)$ & $5(36 \%)$ & $0(0 \%)$ \\
\hline
\end{tabular}

Note: *P value comparing each group versus controls.

Abbreviations: $\mathrm{MH}$, migraine headache; $\mathrm{R}$ to $\mathrm{L}$, right to left.

complete resolution of symptoms; $60 \%, 25 \%$, and $40 \%$, respectively, experienced partial improvement (no statistically significant difference comparing the three groups). Symptoms continued to improve over time after closure of the PFO. At 12-month follow-up, $52 \%$ of patients in Group A, $75 \%$ of patients in Group B, and $80 \%$ of patients in Group C had complete resolution of symptoms. Of the patients who experienced an improvement but not complete resolution of visual symptoms at 3 months, $75 \%, 100 \%$, and $100 \%$ of Groups A, $\mathrm{B}$, and $\mathrm{C}$, respectively, were completely symptom-free by 12-month follow-up. This was true regardless of whether the visual aura was associated with migraine or was independent of the presence of headache. The proportion of patients who experienced complete or partial resolution of their symptoms by 12 months was $76 \%$ in Group A, 75\% in Group B, and $80 \%$ in Group C (not statistically significant comparing all three groups). The observed resolution or improvement in symptoms coincided with resolution of the right to left shunt, as demonstrated by follow-up transcranial Doppler studies. Patients who chose to not have their PFO closed experienced no significant change in their symptoms.

Table 5 shows a comparison between the three study groups for patients with and without PFO closure. Except for an older age at the time of the procedure and a higher prevalence of hyperlipidemia in patients who underwent closure of PFO in Group A, the clinical descriptors in all study groups were similar. As seen in Table 5, a significant number of patients in our study were on preventive medications for migraine, most often topiramate, followed by beta-blockers, calcium channel antagonists, and antidepressants. The majority of the patients continued taking their medications after improvement of their symptoms.

\section{Discussion}

There have been several observational studies over the past 15 years showing an increased incidence of right to left shunt, primarily through a $\mathrm{PFO}$, in patients having migraine headache with aura. ${ }^{7-9,12-15}$ In addition, when the PFO was closed either percutaneously or by surgery, $60 \%-80 \%$ of patients claimed that their migraines were either significantly reduced in frequency and severity, or completely abolished. ${ }^{14-18}$ The underlying hypothesis is that some type of chemical passes through the PFO and enters the cerebral circulation in a high concentration to trigger a spreading cortical depression that is perceived as the transient neurologic deficit of migrainous aura. When the PFO is closed, blood is forced through the pulmonary circulation where these chemicals are metabolized during passage of blood through the capillary endothelium. Some possible chemicals that could act as a trigger for migraine include serotonin and certain amino acids, or sudden hypoxemia or a change in $\mathrm{pH}$. This hypothesis is currently being tested in the PREMIUM trial.

Table 4 Effect of patent foramen ovale closure on patients with visual aura

\begin{tabular}{|c|c|c|c|c|c|c|}
\hline \multirow[t]{2}{*}{ Follow-up } & \multicolumn{2}{|c|}{$\begin{array}{l}\text { Group A } \\
\text { (MH + aura) }\end{array}$} & \multicolumn{2}{|c|}{$\begin{array}{l}\text { Group B } \\
\text { (MH unrelated to aura) }\end{array}$} & \multicolumn{2}{|c|}{$\begin{array}{l}\text { Group C } \\
\text { (aura only) }\end{array}$} \\
\hline & $\begin{array}{l}\text { 3-month } \\
\text { follow-up }\end{array}$ & $\begin{array}{l}\text { I 2-month } \\
\text { follow-up }\end{array}$ & $\begin{array}{l}\text { 3-month } \\
\text { follow-up }\end{array}$ & $\begin{array}{l}\text { I2-month } \\
\text { follow-up }\end{array}$ & $\begin{array}{l}\text { 3-month } \\
\text { follow-up }\end{array}$ & $\begin{array}{l}\text { I2-month } \\
\text { follow-up }\end{array}$ \\
\hline PFO closed (n) & 67 & & 8 & & 5 & \\
\hline Resolved & 17 (25\%) & 35 (52\%) & $4(50 \%)$ & $6(75 \%)$ & $2(40 \%)$ & $4(80 \%)$ \\
\hline Improved & $40(60 \%)$ & $16(24 \%)$ & $2(25 \%)$ & $0(0 \%)$ & $2(40 \%)$ & $0(0 \%)$ \\
\hline No change & 3 (4.5\%) & I (I.5\%) & I (I2.5\%) & I (I2.5\%) & $0(0 \%)$ & $0(0 \%)$ \\
\hline Worse & $4(6.0 \%)$ & $3(4.5 \%)$ & I (I2.5\%) & $0(0.0 \%)$ & $0(0 \%)$ & $0(0 \%)$ \\
\hline Data unavailable & $3(4.5 \%)$ & $12(18 \%)$ & $0(0 \%)$ & I (I2.5\%) & I (20\%) & I (20\%) \\
\hline
\end{tabular}

Abbreviations: $\mathrm{MH}$, migraine headache; $\mathrm{PFO}$, patent foramen ovale. 


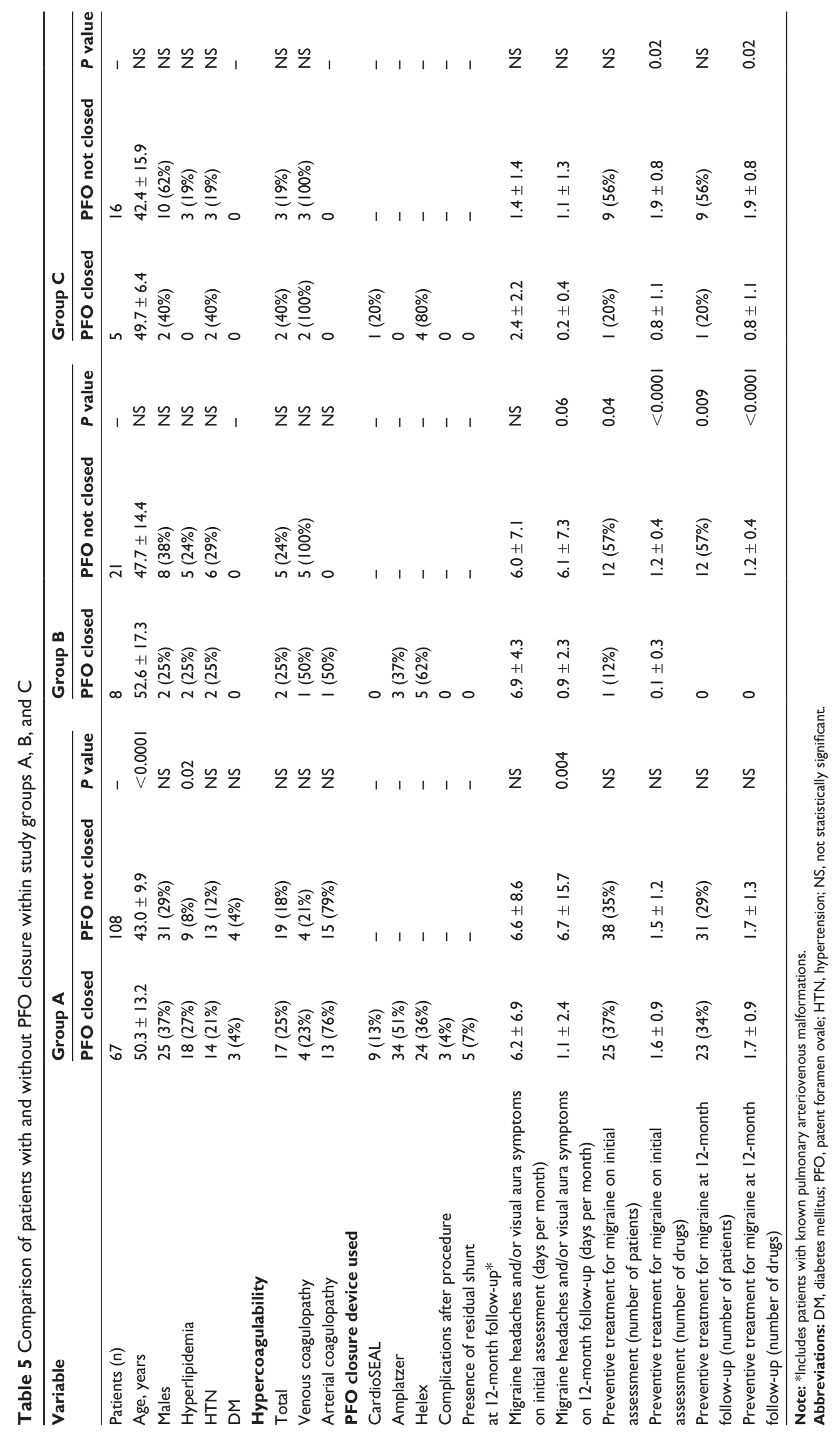


In this study, we demonstrated that visual auras are associated with right to left shunting whether or not there is associated migraine headache. While right to left shunting occurred at a higher frequency $(P<0.0001)$ in patients with visual aura temporally associated with migraine (Group A), visual aura unrelated to the timing of migraine (Group B), and visual aura without any history of headache (Group C) than in controls, the frequency of right to left shunt did not differ between the three groups of patients. In addition, PFO closure resulted in improvement of aura among patients presenting with visual aura, with or without headache, further implying that the response to therapy, and therefore the mechanism of this phenomenon, may be similar between the study groups. Migraine visual aura without headache is present in $3.2 \%$ of the general population, with a biphasic age distribution between the ages of 20-39 years and 60-69 years. ${ }^{2}$ Our study cohort of 590 patients referred for potential PFO-related disorders demonstrated a similar prevalence of visual aura without headache $(21 / 590,3.6 \%)$. The prevalence of right to left shunting in our control population was $18 \%$, similar to previously published data, ${ }^{3-5}$ indicating that our control group was appropriate for comparison with individuals who had visual auras.

Despite these observations suggesting an association between the presence of PFO and visual aura without migraines, right to left shunting of blood is not the only mechanism that produces transient visual disturbances. About $40 \%$ of migraineurs with aura do not have evidence of a right to left shunt. There were seven (33\%) individuals in the current study who had visual aura without headache and no evidence of a right to left shunt. While not statistically significant, there was a trend toward more hypercoagulability in patients with visual auras compared with controls, suggesting that hemorrheologic abnormalities may also play a role. The high prevalence of right to left shunting in this population, which was three times the observed frequency in the control group, is consistent with the hypothesis that intermittent right to left shunting through a PFO permits chemical substances that are usually cleared by the lungs to bypass metabolism by this route and reach the brain at a higher concentration via direct entry into the arterial circulation. ${ }^{18}$ This mechanism is consistent with the high correlation between PFO and migraine with aura, and may explain why symptoms of visual aura are often alleviated after PFO closure.

Based on observational studies, it has been suggested that PFO closure may improve symptoms of migraine ${ }^{16}$ or may reduce the risk of cryptogenic stroke, and randomized clinical trials are in progress to test these hypotheses. Since there is no approval yet for PFO closure, these procedures are currently performed off-label for patients with cryptogenic stroke secondary to paradoxical embolism with the goal of reducing the risk of recurrent strokes.

One of the limitations of this study is the selection of a study cohort consisting of patients with suspected right to left shunting. A better study cohort would have comprised individuals presenting to an ophthalmology clinic with visual aura without headache who agreed to be screened for a shunt by transcranial Doppler. Although we attempted to obtain such a cohort of patients, there were only three individuals who fitted this criterion.

In conclusion, ophthalmologists should be aware that visual auras are not always due primarily to a local ocular process. When a patient presents with a clear history of visual auras without headache, adjunctive testing to evaluate the retina and retinal vasculature, or study of optic nerve function and imaging, are not likely to be helpful in the absence of other findings on history or clinical examination suggesting local pathology. Ophthalmologists are in a position to counsel their patients and refer appropriately if there is any additional concern, in particular a history of transient ischemic attack or cryptogenic stroke. Definitive evidence of the efficacy and safety of PFO closure for migraine visual aura will come from the results of randomized clinical trials currently in progress.

\section{Disclosure/funding source}

Jonathan Tobis is a consultant for AGA Medical Inc, WL Gore Inc, and Coherex Inc. RDL funded in part by the MacDonald Family Foundation. AGA Medical Inc provided the transcranial Doppler system. No other funding from these companies was provided for this study.

\section{References}

1. Headache Classification Committee of the International Headache Society. The International Classification of Headache Disorders. 2nd ed. Cephalalgia. 2004;24 Suppl 1:9-160.

2. Aiba S, Tatsumoto M, Saisu A, et al. Prevalence of typical migraine aura without headache in Japanese ophthalmology clinics. Cephalalgia. 2010;30:962-767.

3. Schwerzman M, Nedeltshev K, Lagger F, et al. Prevalence in size of directly detected patent foramen ovale in migraine with aura. Neurology. 2005;65:1415-1418.

4. Hagen PT, Scholz DG, Edwards WD. Incidence and size of patent foramen ovale during the first 10 decades of life: An autopsy study of 965 normal hearts. Mayo Clin Proc. 1984;59:17-20.

5. Anzola GP, Magoni M, Guindani M, Rozzini L, Dalla Volta G. Potential source of cerebral embolism in migraine with aura: a transcranial Doppler study. Neurology. 1999;52:1622-1625.

6. Lipton RB, Bigal ME, Diamond M, Frietaq F, Reed ML, Stewart WF; AMPP Advisory group. Migraine prevalence, disease burden and the need for preventive therapy. Neurology. 2007;68:343-349.

7. Azarbal B, Tobis J, Suh W, Chan V, Dao C, Gaster R. Association of interatrial shunts and migraine headaches: impact of transcatheter closure. J Am Coll Cardiol. 2005;45:489-492. 
8. Dalla Volta G, Guindani M, Zavarise P, et al. Prevalence of patient ovale in large series of patients with migraines with aura, migraine without aura and cluster headache, and relationship with clinical phenotype. $J$ Headache Pain. 2005;6:328-330.

9. Domitrz I, Mieszkowski J, Kaminska A. Relationship between migraine and patent foramen ovale: a study of 121 patients with migraine. Headache. 2007;47:1311-1318.

10. Van H, Poommipanit P, Shalaby M, Gevorgyan R, Tseng CH, Tobis J. Sensitivity of transcranial Doppler versus intracardiac echocardiography in the detection of right-to-left shunt. JACC Cardiovasc Imaging. 2010;3:343-348.

11. Spencer MP, Moehring MA, Jesurum J, Gray WA, Olsen JV, Reisman M. Power M-mode transcranial Doppler for diagnosis of patent foramen ovale and assessing transcatheter closure. J Neuroimaging. 2004; $14: 342-349$

12. Ferrani G, Malferrari G, Zucco R, Gaddi O, Norina M, Pini LA. High prevalence of patent foramen ovale in migraine with aura. J Headache Pain. 2005;6:71-76.

13. Sztajzel R, Genoud D, Roth S, Mermillod B, Le Floch-Rohr J. Patent foramen ovale, a possible cause of symptomatic migraine: a study of 74 patients with acute ischemic stroke. Cerebrovasc Dis. 2002;13:102-106.
14. Schwerzman M, Wiher S, Nedeltchev K, et al. Percutaneous closure of patient foramen ovale reduces the frequency of migraine attacks. Neurology. 2004;62:1399-1401.

15. Carod-Artal FJ, da Silveira Ribeiro L, Braga H, Kummer W, Mesquita HM, Vargas AP. Prevalence of patent foramen ovale in migraine patients with and without aura compared with stroke patients. A transcranial Doppler study. Cephalalgia. 2006;26:934-939.

16. Trabattoni D, Fabbiocchi F, Montorsi P, et al. Sustained long-term benefit of patent foramen ovale closure on migraine. Catheter Cardiovasc Interv. 2011;77:570-574.

17. Wahl A, Praz F, Findling O, et al. Percutaneous closure of patent foramen ovale for migraine headaches refractory to medical treatment. Catheter Cardiovasc Interv. 2009;74:124-129.

18. Tobis JM, Azarbal B. Does patent foramen ovale promote cryptogenic stroke and migraine headaches? Texas Heart Inst J. 2005;32: $362-365$.
Clinical Ophthalmology

\section{Publish your work in this journal}

Clinical Ophthalmology is an international, peer-reviewed journal covering all subspecialties within ophthalmology. Key topics include: Optometry; Visual science; Pharmacology and drug therapy in eye diseases; Basic Sciences; Primary and Secondary eye care; Patien Safety and Quality of Care Improvements. This journal is indexed on

Submit your manuscript here: http://www.dovepress.com/clinical-ophthalmology-journal

\section{Dovepress}

PubMed Central and CAS, and is the official journal of The Society of Clinical Ophthalmology (SCO). The manuscript management system is completely online and includes a very quick and fair peer-review system, which is all easy to use. Visit http://www.dovepress.com/ testimonials.php to read real quotes from published authors. 